\title{
Apparent obstruction of the superior vena cava and a continuous murmur: signs of a fistula between a vein graft aneurysm and the right atrium
}

\author{
Mark P Richardson, Surendran I Thuraisingham, John Dunning
}

\begin{abstract}
A previously undescribed complication of a saphenous vein aortocoronary bypass graft, namely formation of a fistula between a vein graft aneurysm and the right atrium is reported. A patient presented with a continuous murmur and a combination of signs suggesting superior vena cava obstruction. This pathology was shown by both echocardiography and angiography. Surgical treatment was attempted.
\end{abstract}

(Br Heart J 1992;68:412-3)

Aneurysms of saphenous vein grafts, first recognised in 1975, are now a well recognised complication of coronary artery bypass surgery. ${ }^{1}$ Such aneurysms may be further complicated by thromboemboli causing ischaemia, ${ }^{2}$ myocardial infarction, ${ }^{3}$ rupture, ${ }^{4}$ or by formation of a fistula to the right ventricle. ${ }^{5}$ We report here a case of formation of a fistula between an aortocoronary saphenous vein graft and the right atrium. To our knowledge this has not previously been reported.

\section{Case report}

A white man born in 1917 underwent xenograft of the aortic valve and saphenous vein

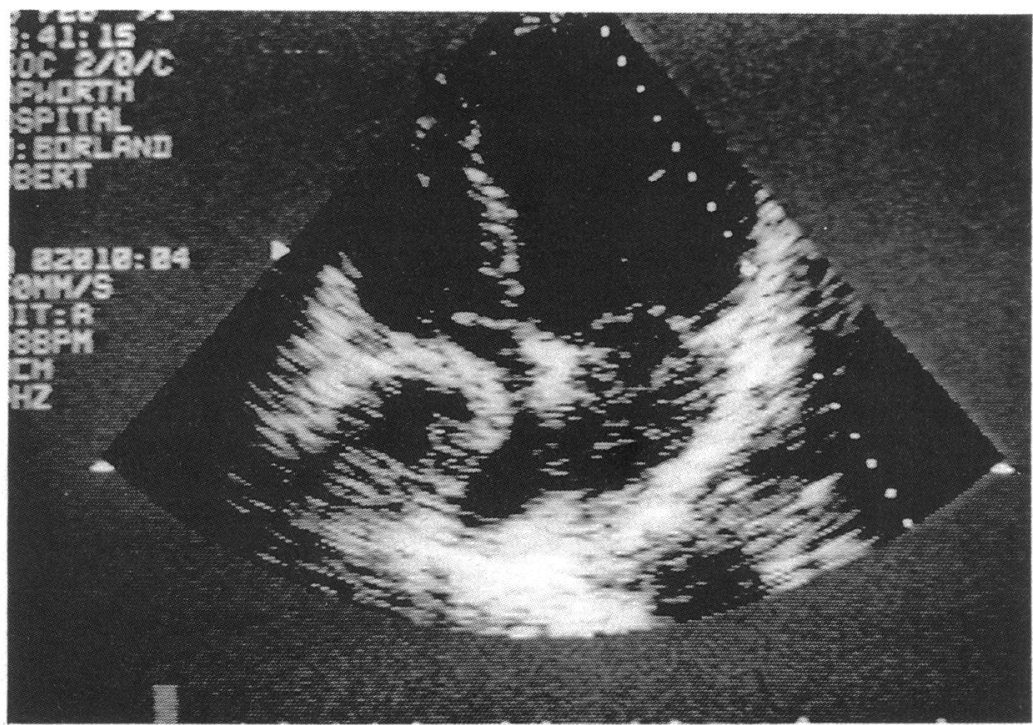

Figure 1 Four chamber transthoracic echocardiogram showing doughnut shaped right atrial abnormality. bypass grafting to left anterior descending, circumflex, and right coronary arteries at another hospital in 1980 . Subsequently he was free of symptoms for nine years, but had a recurrence of stable, non-limiting angina for two years before his admission to hospital. Two days before admission to hospital he experienced a sudden onset of severe right shoulder and neck pain that worsened steadily. He was breathless. On admission to a local district general hospital his physical signs suggested biventricular failure, and diuretic treatment was started. There was no improvement. Echocardiography showed a right atrial abnormality that prompted immediate referral to the regional cardiac centre.

On arrival at Papworth Hospital the patient was still experiencing severe right shoulder, neck, and back pain. He was confused and clammy. He had a regular, collapsing pulse of 90 per minute, and a blood pressure of $130 /$ $60 \mathrm{~mm} \mathrm{Hg}$ was recorded in both arms. Peripheral pulses were all present, equal, and symmetrical. Particularly striking was the grossly raised venous pressure, with distention of the neck veins and a suffused face. A continuous murmur was noted that was heard loudest at the left and right sternal edges. Bilateral basal crepitations were found but there was no peripheral oedema. Investigations showed a normal full blood count, normal electrolytes, but impaired renal function with $25 \mathrm{mmol} / \mathrm{l}$ urea and $330 \mu \mathrm{mol} / 1$ creatinine. The electrocardiogram showed sinus tachycardia with left bundle branch block and left ventricular hypertrophy. A chest radiograph showed right basal shadowing with no evidence of left ventricular failure. Echocardiography showed a circular, doughnut shaped area of high echo density with a diameter of about $4 \mathrm{~cm}$ in the region of the right atrium (fig 1). It was unclear what this was and immediate cardiac catheterisation was undertaken.

An aortogram through the right femoral artery showed a normal arch, with no evidence of dissection, or a ruptute of an aneurysm in the sinus of Valsalva. Left ventricular function was good. Contrast was seen in filling the right atrium and the vein graft to the right coronary artery, which was grossly dilated in its mid third (fig 2). A fistula clearly existed between the graft and the right heart cham- 


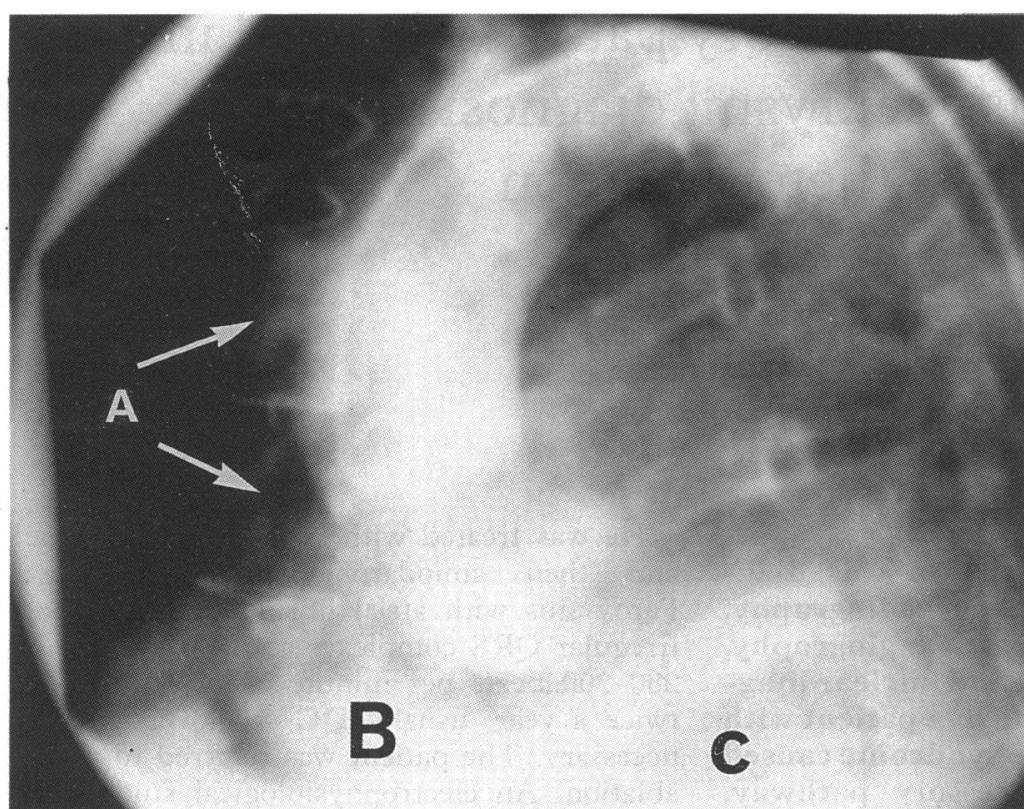

Figure 2 Aortogram in left anterior oblique position showing opacification of the right coronary artery graft $(A)$ with contrast filling the aneurysm $(B)$ and the right atrium (C).

bers, and immediate surgery was undertaken.

The patient was transferred to the operating theatre where electrocardiographic, central venous and arterial pressure monitoring were started. A general anaesthetic was given and median sternotomy was performed. The pericardium was open from previous surgery and there was no free fluid. Arterial and venous cannulation were performed through the left femoral vessels. This allowed cardiopulmonary bypass (CPB) to be established. An atrial venous cannula was connected to the circuit via a $\mathrm{Y}$-shaped connection the venous side and placed in the right atrium once the heart was further dissected.

The previous vein grafts were identified; the graft to the circumflex system appeared as a thin cord with no flow. The graft to the left anterior descending artery was patent. The graft to the right coronary artery was paten but was dilated with an aneurysm in it's midportion, which was densely adherent to the right atrium. During further dissection of the heart, sinus rhythm was lost and difficulties were experienced in maintaining CPB in the absence of an aortic cross clamp. When the right coronary graft was cross clamped, systemic pressures returned and normal bypass was achieved. It was apparent that the aortic return was passing through the right graft, across the fistula to the right atrium and returning directly as venous drainage.

The fistula was excised, the right atrium closed, and the existing right coronary graft ligated proximal to the fistula. There was good back flow from the distal portion of the graft, which was also ligated. Inotropic support was started and weaning from CPB was attempted. Biventricular failure supervened and CPB could not be weaned. The pump was switched off and the patient declared dead.

At postmortem examination it was noted that there was severe atheroma of the aorta and major arteries. The right coronary graft was arterialised with severe ulcerated atheroma. The aneurysm of its midportion was nine $\mathrm{cm}$ in circumference and contained old and recent thrombi. The right coronary artery was less occluded distally than the other native vessels. The right atrium was slightly dilated and the right ventricle was both dilated and hypertrophied. The left atrium and ventricle were not dilated and the aortic xenograft undamaged.

\section{Discussion}

It is likely that the acute presentation of this case resulted from the acute formation of the fistula from the aneurysm of the right coronary to the right atrium with a resulting significant shunt from aorta to right atrium. Surgery was clearly the only therapeutic option, but this patient's ischaemic myocardium did not function adequately after bypass despite successful repair of the fistula.

The mechanisms responsible for formation of aneurysms in saphenous vein grafts have been suggested to include distension of the vessel wall at the site of venous valves which lack circular muscle, ${ }^{6}$ and atheroma. ${ }^{7}$ Furthermore, such aneurysms are more common five or more years after surgery and in patients with hyperlipidaemia. ${ }^{8}$

It is notable that this complication was shown by both angiography and echocardiography. Aneurysm of coronary artery vein grafts has previously been shown by transoesophageal echocardiography on one occasion $^{3}$ but to our knowledge never by transthoracic echocardiography. Its appearance is highly unusual.

The clinical signs in this patient are unique. His venous pressure was considerably raised with a continuous murmur. In a patient who has had an aortocoronary graft such a murmur has been said to be indicative of the inadvertent anastomosis of the distal end of the graft to a coronary vein. ${ }^{9}$ We would like to add to this diagnosis that of a fistula between an aortocoronary graft and the right atrium.

We thank Dr Leonard Shapiro for his assistance in the preparation of this article.

1 Riahi M, Vasu CM, Tomatis LA, Schlosser RJ, Zimmerman G. Aneurysm of saphenous vein bypass graft to coronary artery. $J$ Thorac Cardiovasc Surg 1975;70:358-9.

2 Taliercio CP, Smith HC, Pluth JR, Gibbons RJ. Coronary artery venous bypass graft aneurysm with symptomatic coronary artery emboli. J Am Coll Cardiol 1986;7:453-7.

3 Dzavik V, Lemay M, Chan K-L. Echocardiographic diagnosis of an aortocoronary venous bypass graft aneurysm. Am Heart $J$ 1989;118:619-21.

4 Shapeero LG, Guthaner DF, Swerdlow CD, Wexler L. Rupture of a coronary bypass graft aneurysm: CT evaluation and coil occlusion therapy. Am J Roentgenol 1983; 141:1060-62.

5 Riahi M, Stone KS, Hanni CL, Fierens E, Dean RE. Right ventricular-saphenous vein graft fistula. $J$ Thorac Cardiovasc Surg 1984;87:626-8.

6 Benchimol A, Harris CL, Desser KB, Fleming H. Aneurysms of an aortocoronary saphenous vein bypass Aneurysms of an aortocoronary saphenous vein bypass

7 Pintar K, Barboriak JJ, Johnson D. Atherosclerotic aneurysm in aortocoronary vein graft. Arch Pathol Lab aneurysm in aortoco

8 Teja K, Dillingham R, Mentzer RM. Saphenous vein aneurysms after aortocoronary bypass grafting: postoperative interval and hyperlipidaemia as determining factors. Am Heart J 1987;113:1527-9.

9 Vieweg WVR. Continuous murmur following bypass surgery. Chest 1981;79:4-5. 